\title{
Exigências de energia e composição da carcaça de galos reprodutores pesados em função do consumo energético na fase de reprodução ${ }^{1}$
}

\section{Carlos Augusto Quadro Borges ${ }^{2}$, Horacio Santiago Rostagno ${ }^{3}$, José Humberto Vilar da Silva 4 , Luiz Fernando Teixeira Albino ${ }^{3}$, Ciro Alexandre Alves Torres ${ }^{3}$, José Jordão Filho ${ }^{5}$, Marcelo Luís Gomes Ribeiro4, 5}

\footnotetext{
1 Parte da tese de Doutorado do primeiro autor apresentada ao DZO/CCA/UFV, Viçosa - MG.

2 C Borges Consultoria. Consultor Técnico em Produção e Nutrição Animal.

${ }^{3}$ DZO/CCA/UFV, Viçosa - MG. CEP: 36571-000.

${ }^{4} D A P / C F T / U F P B$, Bananeiras - PB e PPGZ - CCA/UFPB, Areia - PB.

5 Doutorado Integrado em Zootecnia, PIDZ/CCA/UFPB, Areia - PB.
}

RESUMO - Dois experimentos foram realizados para estimativa da exigência e da composição de carcaça de machos reprodutores de corte em resposta a cinco níveis de ingestão de energia metabolizável (EM). Para avaliar o peso corporal, o volume de sêmen, a concentração espermática, a motilidade, o vigor e a fertilidade dos espermatozóides, foram selecionadas 450 fêmeas e 75 machos da linhagem Cobb-500 e, para avaliar a composição química da carcaça em MS, PB e gordura em função do consumo de energia, foram utilizados 30 machos. O delineamento experimental foi o inteiramente casualizado com cinco tratamentos $(290,310,330,350$ e $370 \mathrm{kcal}$ de EM/ave/dia). No ensaio de desempenho reprodutivo, cada tratamento foi composto de 15 repetições de um galo e seis fêmeas e, no ensaio de avaliação da carcaça, cada tratamento continha duas repetições de três galos (três abatidos às 45 e três às 61 semanas de idade). A motilidade, o vigor e a fertilidade dos espermatozóides foram influenciados de forma quadrática pelo nível de ingestão de EM. O peso corporal e os teores de gordura e proteína da carcaça cresceram linearmente com o aumento do consumo de EM. Com base nas estimativas obtidas para motilidade, vigor e fertilidade, recomenda-se nível médio de $347 \mathrm{kcal}$ de EM/galo/dia para atender às necessidades de machos reprodutores de 26 a 61 semanas de idade.

Palavras-chave: desempenho reprodutivo, fertilidade, nutrição, sêmen

\section{Energy requirements and carcass composition of male broiler breeders as a function of energy intake during the reproduction period}

\begin{abstract}
Two trials were carried out to estimate the nutritional requirement and carcass composition of male broiler breeders according to five levels of metabolizable energy (ME) ingestion. Four hundred and fifty females and 75 males of Cobb-500 strain were selected to evaluate body weight, semen volume, spermatic concentration, motility, vigor and fertility of spermatozoa. Thirty males were used for evaluation of carcass chemical composition (DM, CP and crude fat [CF]) as a function of energy intake. The experiment was analyzed as a completely randomized design with five treatments (290, $310,330,350$ and $370 \mathrm{kcal}$ of ME/rooster/day). In the first trial (reproductive performance), each treatment was represented by 15 replicates of one rooster and six females. In the second trial (carcass evaluation), each treatment consisted of two replicates of three roosters (three slaughtered at 45 weeks and three at 61 weeks of age). Treatment quadract effect on motility, vigor and the fertility of spermatozoa was observed. Body weight and contents of fat and CP in the carcass increased linearly as ME intake increased. Based on the estimates of mobility, vigor and fertility, the $347 \mathrm{kcal}$ of ME/rooter/day level is recommended to meet the requirements of male broiler breeders from 26 to 61 weeks of age.
\end{abstract}

Key Words: fertility, nutrition, performance reproductive, semen

\section{Introdução}

O grande crescimento da avicultura mundial, principalmente nas últimas décadas, foi atribuído à eficiência de produção de carne de frangos a custos mais competitivos. As linhagens de conformação avícolas destinadas à produção de carne são, prioritariamente, selecionadas para ganho de peso. Frangos de corte originados destas matrizes apresentam característica típica de melhor conversão alimentar, melhor conformação e melhor rendimento de carcaça, fatores importantes para a rentabilidade das indústrias.

Estas qualidades são desejadas em frangos de corte, mas são problemáticas para o desempenho reprodutivo das matrizes, pois sabe-se que, na genética, quando se busca 
selecionar uma característica desejável, quase sempre, ela é acompanhada por uma indesejável. Este fato foi observado por Robinson (1993), principalmente em machos, com diminuição do desempenho reprodutivo, em virtude das correlações genéticas negativas entre crescimento e características de reprodução.

O manejo nutricional da matriz tem recebido maior ênfase, enquanto, a nutrição do galo tem sido relegada ao segundo plano. Apesar de a proporção de machos representar apenas $10 \%$ em relação à das fêmeas, os machos contribuem com $50 \%$ da carga genética do plantel e são fundamentais para a fertilidade em um plantel. Entretanto, as informações atuais sobre os fatores nutricionais que influenciam o desempenho reprodutivo não estão de acordo com a importância dos galos no processo reprodutivo (Danikowski et al., 2002).

O sucesso da fertilidade por monta natural está associado a vários fatores, incluindo os genéticos (Edens, 1983) e os não-genéticos, como a temperatura e o fotoperíodo (Samara et al., 1996; Boni \& Paes, 1999; Renema et al., 2001), os sociais e os nutricionais. Considerando que a herdabilidade das características de eficiência reprodutiva é relativamente baixa, os fatores não genéticos são importantes para o desempenho reprodutivo das matrizes em nível comercial.

A prática de alimentação de machos e fêmeas separados por sexo na fase de reprodução foi adotada no Brasil no final da década de 80 e contribuiu para melhorar significativamente a fertilidade e a eclodibilidade dos plantéis de matrizes, aumentando o interesse em conhecer as exigências nutricionais de machos ao longo dos anos (Wilson et al., 1987; Sexton et al., 1989; Revington et al., 1991; Couto et al., 1998; Rodenas et al., 2005). Atualmente, esta prática é adotada na maioria dos países do mundo, pois permite o arraçoamento de galos reprodutores com base nas suas próprias exigências nutricionais, servindo para controlar o consumo alimentar e o peso corporal, evitando a obesidade do plantel de matrizes.

Um importante fator que onera o custo de produção na indústria avícola de corte é a nutrição de machos e este custo está associado às necessidades de crescimento e de mantença de machos reprodutores. A alimentação contribui com aproximadamente $70 \%$ do custo total de produção, sendo evidente a necessidade de estimar as reais exigências nutricionais dos galos nas diferentes fases de criação. Quanto mais informações disponíveis sobre as exigências nutricionais de galos reprodutores, mais a alimentação com excesso de determinados nutrientes será minimizada, resultando em economia de alimentos e significativa melhora na eficiência reprodutiva.
Como a energia é o nutriente mais caro de uma ração e existe carência de pesquisa nesta área para galos reprodutores, realizou-se este trabalho com o objetivo de obter estimativas das exigências nutricionais em energia de galos reprodutores na fase de reprodução.

\section{Material e Métodos}

Os trabalhos foram realizados na Granja avícola de Melhoramento Genético da Universidade Federal de Viçosa, situada no município de Viçosa, MG.

As fêmeas e os machos foram criados em boxes separados desde o primeiro dia até as 23 semanas de idade. No período de 1 a 28 dias de idade, as aves receberam ração à vontade com uma dieta contendo $18 \%$ de PB e $2.850 \mathrm{kcal}$ de energia metabolizável aparente por quilograma de ração (EMA/kg). A dieta na recria (5 a 23 semanas de idade) continha $16 \%$ de $\mathrm{PB}$ e $2.850 \mathrm{kcal} \mathrm{EM} / \mathrm{kg}$ de ração. No período de 5 a 15 semanas de idade, as aves foram submetidas à restrição alimentar, com água à vontade e arraçoamento quatro dias sim, três dias não. Na fase de 16 a 19 semanas de idade, o fornecimento de ração passou a ser feito cinco dias sim e dois dias não. A partir desta fase, as aves receberam arraçoamento diário com quantidades controladas de ração.

Da 4à 24- semana de idade, aproximadamente $10 \%$ dos galos foram pesados para o controle do peso e do arraçoamento. As exigências nutricionais e a quantidade de ração para os galos seguiram as recomendações do manual da linhagem COBB-500.

$\mathrm{O}$ acasalamento das aves foi realizado às 24 semanas de idade, sendo distribuídas seis fêmeas e um macho por boxe, de acordo com o peso corporal e a maturidade sexual. Os boxes (2,0 x 1,5 m), com piso de concreto coberto com cama de maravalha, continham um bebedouro pendular e dois comedouros tubulares (um para as fêmeas e outro para os machos, colocado mais alto, de modo a permitir somente o acesso dos machos). O galpão utilizado nos experimentos, construído em alvenaria (14 x 104 m), com pé-direito de $3,0 \mathrm{~m}$, extremidades fechadas com paredes e laterais compostas por muretas $(0,30 \mathrm{~m})$ e telhado constituído de telha de cimento-amianto ( $6 \mathrm{~mm}$ de espessura), continha 280 boxes, cada um com um ninho.

Os programas de luz e vacinação foram estabelecidos de acordo com a recomendação do manual da linhagem. Ao completaram 27 semanas de idade, as aves foram submetidas a um regime de 17 horas de luz/dia, com luz natural mais luz artificial.

Foram utilizados 525 animais (450 fêmeas e 75 machos) da linhagem Cobb-500, durante a fase experimental de 26 a 61 semanas de idade. 
Os teores de PB do milho, do farelo de soja e do farelo de trigo foram determinados por análise proximal, realizada no Laboratório de Nutrição do Departamento de Zootecnia da UFV, segundo técnica descrita por Silva (1991).

Foi adotado um delineamento inteiramente casualisado, com cinco tratamentos (um galo e seis fêmeas) e 15 repetições. Os tratamentos consistiram de cinco rações contendo os níveis 2.230, 2.385, 2.538, 2.692 e $2.850 \mathrm{kcal}$ de EMA/kg, fornecidas na proporção de $130 \mathrm{~g} / \mathrm{galo} / \mathrm{dia}$, correspondendo, respectivamente, aos consumos de 290, 310, 330, 350 e $370 \mathrm{kcal}$ EMA/galo/dia. As rações experimentais, à base de milho, farelo de soja e farelo de trigo, foram formuladas para atender ou exceder as exigências das aves em todos os nutrientes (exceto proteína nas duas primeiras dietas), segundo sugestões de Rostagno et al. (2000) (Tabela 1). O fornecimento das dietas foi equalizado em $130 \mathrm{~g}$ a partir de 27 semanas de idade, enquanto a água foi oferecida à vontade.

Avaliou-se o peso corporal e a composição da carcaça (MS, PB e gordura bruta) e efetuaram-se análises quantitativa (volume de sêmen e concentração espermática) e qualitativas do sêmen (motilidade, viabilidade e fertilidade). As análises das variáveis, com exceção da composição da carcaça, foram feitas em intervalos de seis semanas a partir da 37 a semana, ou seja, às 37, 43, 49 e 55 semanas de idade.

O volume de sêmen foi obtido por meio da leitura direta em seringas de insulinas. A técnica de coleta do sêmen foi a da massagem abdominal proposta por Burrows \& Quinn (1937). Foi necessário jejum de 24 horas para redução da contaminação do sêmen durante a coleta. O sêmen foi coletado pela manhã em um copo plástico descartável de $50 \mathrm{~mL}$.

Para a análise da concentração espermática, uma amostra de sêmen foi obtida e colocada em um tubo capilar, sendo submetida a centrifugação por 10 minutos em uma centrífuga de microhematócrito. O sêmen fresco foi preparado em camada fina sobre uma lâmina, diluído com uma solução salina para possibilitar a visualização das células individualmente. O número total de células foi calculado pelo produto da concentração com o volume do ejaculado, segundo metodologia de Martin Rillo et al. (1996).

A motilidade e o vigor foram estimados pela porcentagem e pelo tipo de movimento destas células em microscópio com o aumento de 400x. A fertilidade foi avaliada às 50 a 60

Tabela 1 - Composições alimentar e nutricional das rações experimentais ${ }^{1}$

Table 1 - Ingredient and chemical compositions of the experimental diets

\begin{tabular}{|c|c|c|c|c|c|}
\hline \multirow[t]{2}{*}{$\begin{array}{l}\text { Ingrediente } \\
\text { Ingredient }\end{array}$} & \multicolumn{5}{|c|}{$\begin{array}{c}\text { Consumo de EM (g/ave/dia) } \\
\text { ME intake (g/bird/day) }\end{array}$} \\
\hline & 290 & 310 & 330 & 350 & 370 \\
\hline Milho (Corn) & 39,900 & 47,900 & 55,840 & 63,340 & 71,000 \\
\hline Farelo de trigo (Wheat meal) & 41,980 & 32,630 & 23,300 & 15,530 & 7,670 \\
\hline Farelo de soja (45\%) (Soybean meal) & 3,500 & 5,500 & 7,500 & 9,000 & 10,500 \\
\hline Fosfato bicálcico (Dicalcium phosphate) & 1,550 & 1,630 & 1,720 & 1,800 & 1,860 \\
\hline Calcário (Limestone) & 1,500 & 1,450 & 1,400 & 1,350 & 1,300 \\
\hline Óleo vegetal (Vegetal oil) & 0,500 & 0,500 & 0,500 & 0,500 & 0,500 \\
\hline Sal comum (Salt) & 0,350 & 0,350 & 0,350 & 0,350 & 0,350 \\
\hline DL-metionina (99\%) (Methionine) & 0,084 & 0,080 & 0,074 & 0,070 & 0,064 \\
\hline L-lisina $\mathrm{HCl}($ L-lysine $)$ & 0,190 & 0,170 & 0,150 & 0,130 & 0,110 \\
\hline Premix vitamínico ${ }^{1}$ (Vitamin premix) & 0,100 & 0,100 & 0,100 & 0,100 & 0,100 \\
\hline Premix mineral $^{2}$ (Mineral premix) & 0,050 & 0,050 & 0,050 & 0,050 & 0,050 \\
\hline BHT (Antioxidant) & 0,010 & 0,010 & 0,010 & 0,010 & 0,010 \\
\hline Inerte $^{3}$ (Inert) & 10,280 & 9,620 & 9,000 & 7,770 & 6,460 \\
\hline Total & 100,000 & 100,000 & 100,000 & 100,000 & 100,000 \\
\hline \multirow{2}{*}{\multicolumn{6}{|c|}{$\begin{array}{l}\text { Composição química } \\
\text { Chemical composition } \\
\end{array}$}} \\
\hline & & & & & \\
\hline $\mathrm{EM}(A M E n)(\mathrm{kcal} / \mathrm{kg})$ & 2.230 & 2.385 & 2.538 & 2.692 & 2.850 \\
\hline $\mathrm{PB}(C P)(\%)$ & 12,00 & 12,00 & 12,00 & 12,00 & 12,00 \\
\hline $\mathrm{Ca}(\%)$ & 1,00 & 1,00 & 1,00 & 1,00 & 1,00 \\
\hline Fósforo disponível (Available P) (\%) & 0,45 & 0,45 & 0,45 & 0,45 & 0,45 \\
\hline Lisina (Lysine) $(\%)$ & 0,60 & 0,60 & 0,60 & 0,60 & 0,60 \\
\hline Met + Cis $($ Met + Cys $)(\%)$ & 0,50 & 0,50 & 0,50 & 0,50 & 0,50 \\
\hline Metionina (Methionine) (\%) & 0,27 & 0,27 & 0,27 & 0,27 & 0,27 \\
\hline
\end{tabular}

${ }^{1}$ Rovimix aves reprodução (Roche) - Composição/kg do produto(Composition/kg of product): vit. A - 15.000.000 UI; vit. D - 2.000.000 UI; vit. E - 20.000 UI; vit. $\mathrm{K}_{3}-3 \mathrm{~g}$; vit. $\mathrm{B}_{2}-5 \mathrm{~g}$; vit. $\mathrm{B}_{6}-5 \mathrm{~g}$; vit. $\mathrm{B}_{12}-20 \mathrm{mg}$; ácido nicotínico (nicotinic acid)- $25 \mathrm{mg}$; ácido fólico (folic acid)2 g; ácido pantotênico (pantothenicacid) - $8 \mathrm{~g}$; biotina - $100 \mathrm{mg}$; colina (choline) - $200 \mathrm{~g}$; veículo (vehicle) q.s.p. - $1000 \mathrm{~g}$.

2 Roligomix aves (Roche) composição/kg do produto (Composition/kg of product): Mn - $80 \mathrm{~g} ; \mathrm{Zn}-50 \mathrm{~g} ; \mathrm{Fe}-80 \mathrm{~g} ; \mathrm{Cu}-10 \mathrm{~g} ; \mathrm{Co}-2 \mathrm{~g} ; \mathrm{I}-1 \mathrm{~g} ; \mathrm{veículo} \mathrm{(vehicle)}$ q.s.p.

3 Inerte: areia lavada (Washed sand). 
semanas de idade dos animais, pelo número de pintos eclodidos do montante de ovos incubados. Todos os ovos produzidos por boxe foram coletados durante cinco dias consecutivos, sendo identificados e submetidos à desinfecção com a fumigação em formol e permanganato de potássio. Ao término do período de coleta, os ovos foram incubados em incubadora semi-automática. No $7 \underline{0}$ dia de incubação, todos os ovos foram observados por meio de ovoscópio, descartando-se os ovos inférteis.

Para análise de carcaça, foram alojados 30 machos em dez boxes (três por tratamento e boxe); 15 foram abatidos na 45므 semana e os demais na 61a semana de idade para análise dos teores de MS, PB e gordura bruta (GB) da carcaça.

Os galos foram abatidos e as carcaças foram depenadas e moídas em cutter, coletando-se, em seguida, amostras individuais, que foram pré-secas em estufa por 72 horas a $60^{\circ} \mathrm{C}$. Posteriormente, as amostras foram identificadas e enviadas para o laboratório de nutrição da empresa Perdigão Agroindustrial para se proceder à análise de MS gordura e PB da carcaça.

As análises estatísticas foram realizadas utilizando o programa SAEG - Sistema de Análises Estatística e Genética, desenvolvido pela Universidade Federal de Viçosa UFV (1982). As estimativas das exigências de energia foram estabelecidas por meio do modelo de regressão polinomial, considerando o valor do $\mathrm{R}^{2}$ e a resposta biológica das aves.

\section{Resultados e Discussão}

Conforme demonstrado na Tabela 2 , houve efeito linear $(\mathrm{P} \leq 0,05)$ dos níveis de energia consumidos sobre o peso corporal dos galos (Figura 1). O peso corporal esteve diretamente relacionado à ingestão de energia, apresentando correlação positiva, como observado por Sexton et al. (1989).

Segundo Hocking \& Duff (1989), o aumento do peso corporal decorrente do consumo de energia torna os machos mais susceptíveis às desordens mecânicas envolvendo pés e problemas de pernas e estes problemas acabam interferindo na monta natural. O excesso de energia é armazenado principalmente na forma de gordura (Pearson \& Herron, 1981; Silva et al., 2001; 2003) e resulta em aumento do peso corporal e redução da eclodibilidade e fertilidade.

Apesar dos efeitos provocados pelo excesso de consumo de energia, os matrizeiros ainda resistem em adotar um programa nutricional exclusivo para machos, sob a alegação de dificuldades de manejo, da possibilidade de cometerem erros e do não convencimento da melhoria do desempenho reprodutivo. Entretanto, o excesso de peso corporal

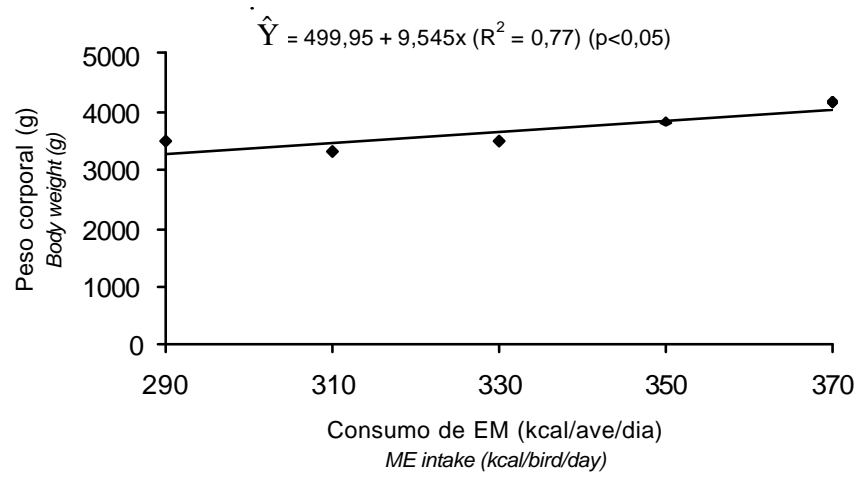

Figura 1 - Efeito do consumo de EM sobre o peso corporal de galos reprodutores.

Figure 1 - Effect of dietary EM intake on body weight of male broiler breeders.

Tabela 2 - Peso corporal (PC), volume de sêmen (VS), concentração espermática (CE), motilidade (MOT), vigor (VIG), fertilidade (FER) e teores de MS, gordura bruta (GB) e PB na carcaça dos galos em função do consumo EM (CEM)

Table 2 - Body weight (BW), semen volume (SV), spermatic concentration (SC), motility (MOT), vigor (VIG), fertility (FER) and DM, crude fat (CF) and CP in the roosters carcass according to the dietary ME intake (MEI)

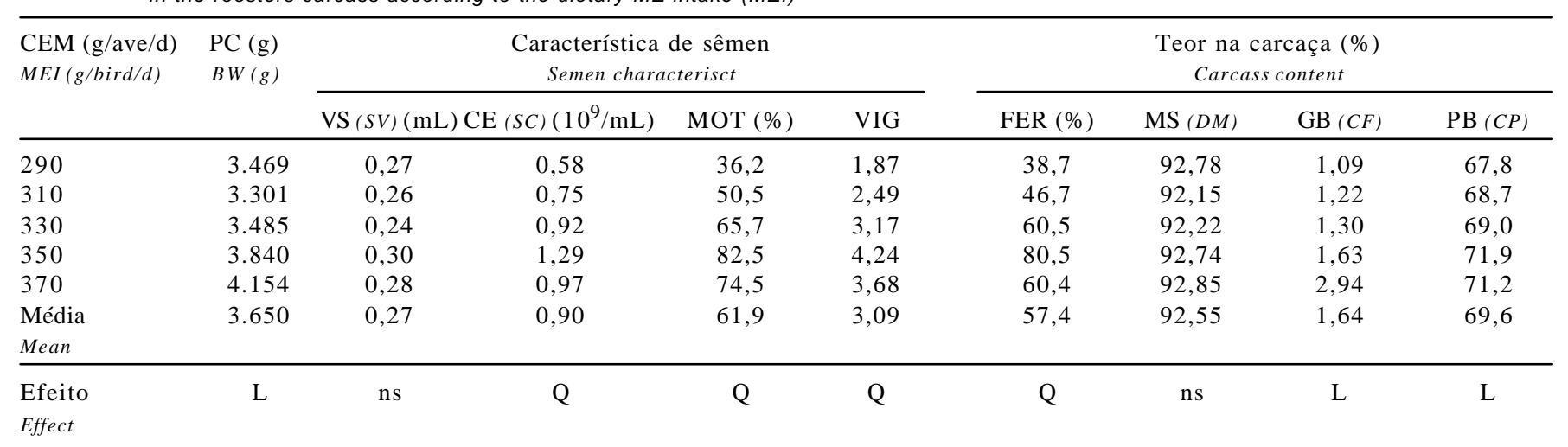

$\mathrm{ns}=$ não-significativo $(\mathrm{P}>0,05)$ (Not significant effect).

$L=$ efeito linear $(P>0,05)$ (Linear effect).

$Q=$ efeito quadrático $(P>0,05)$ (Quadratic effect). 
e a baixa fertilidade dos plantéis de matrizes pesadasresulta na substituição de parte ou de todos os machos com 45 semanas de idade para melhorar a fertilidade do lote.

O consumo de energia não afetou o volume de sêmen, mas a concentração espermática $(\dot{P} \leq 0,05)$ apresentou efeito quadrático, conforme o modelo de regressão $\hat{\mathrm{Y}}=-16,4253+0,0993058 \mathrm{X}-0,000140728 \mathrm{X}^{2}, \mathrm{r}^{2}=0,94$, com estimativa de exigência diária de EM de354 kcal/galo/dia. Este resultado sugere que a falta ou o consumo excessivo de EM deve afetar a concentração do sêmen e a fertilidade do plantel de matrizes. Rutz et al. (1999) encontraram correlação positiva entre a concentração espermática e a fertilidade. A importância da concentração espermática foi ressaltada por Bongalhardo et al. (2000), que sugeriram o uso desta característica como critério de seleção de reprodutores com a finalidade de aumentar a fertilidade do plantel de matrizes.

A falta de efeito significativo do aumento do nível de ingestão de EM sobre o volume de sêmen pode ter sido causada pelo aumento do peso dos galos. No último nível de consumo de EM, o peso corporal dos galos foi superior a $4 \mathrm{~kg}$, influenciando negativamente o resultado desta variável. Resultado semelhante foi observado por Rodenas et al. (2005).

O volume de sêmen e a concentração espermática podem ser insuficientes para avaliar a capacidade reprodutiva dos galos, sendo necessário observar os índices de motilidade e a penetração do espermatozóide no óvulo (McDaniel, 1997), considerando que este deve se deslocar, contra o peristaltismo, da cloaca e fecundar o óvulo nos 15 minutos em que a gema passa pelo infundíbulo (Bellairs \& Osmond, 1998).

A motilidade e o vigor dos espermatozóides foram afetados de forma quadrática $(\mathrm{P}<0,05)$ pelos níveis crescentes de consumo de EM, com exigências estimadas em $364 \mathrm{kcal}$ (Figura 2) e $324 \mathrm{kcal}$ (Figura 3), respectivamente.

Segundo Froman \& Feltmann (1998), a fertilidade do plantel de matrizes é afetada pela motilidade espermática, de modo que galos com fenótipo para alta motilidade apresentam maior fertilidade e maior conteúdo de ATP no esperma que aqueles com fenótipos para baixa motilidade. Froman et al. (2003) comentaram que a motilidade espermática é um processo dependente da síntese de ATP no esperma do galo, existindo uma interação entre a motilidade e o nível de ATP na mitocôndria do esperma. Neste estudo, o aumento do consumo de EM da ração pode justificar o aumento da motilidade espermática no nível de ingestão de 364 kcal EM/ galo/dia pelo nível ótimo de ATP disponível no esperma.

$\mathrm{O}$ aumento da motilidade espermática tem sido também correlacionado à presença de lipídeos poliinsaturados (Cerolini, et al., 2003) e ao nível de proteína da dieta (Revington et al., 1991).

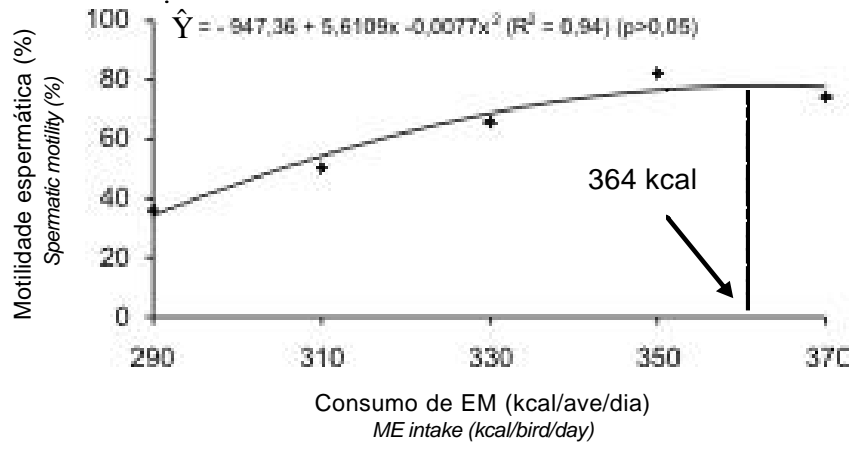

Figura 2 - Efeito do consumo de EM sobre a motilidade dos espermazóides.

Figure 2 - Effect of dietary ME intake on spermatic motility of male broiler breeders.

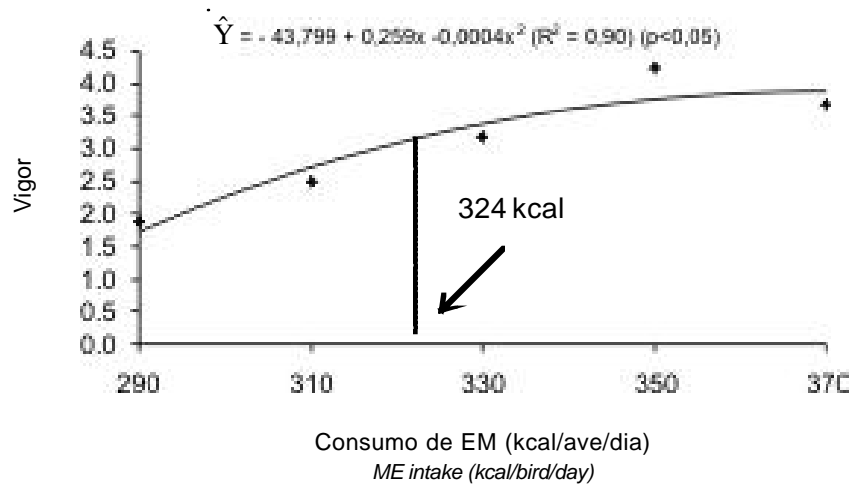

Figura 3 - Efeito do consumo de EM sobre o vigor dos espermatozóides e galos.

Figure 3 - Effect of dietary ME intake on spermatozoa vigor of male broiler breeders.

A fertilidade foi afetada quadraticamente $(\mathrm{P}<0,05)$, conforme o modelo de regressão polinomial $\hat{\mathrm{Y}}=-1035,2+6,2789 \mathrm{X}-0,0089 \mathrm{X}^{2}\left(\mathrm{r}^{2}=0,76\right)$, com estimativa de $353 \mathrm{kcal} / \mathrm{ave} / \mathrm{dia}$. A fertilidade em um sistema de monta natural está relacionada ao peso corporal e ao tamanho dos galos, pois reflete na agilidade do acasalamento. Desse modo, a influência da obesidade na função reprodutiva de machos reprodutores parece estar mais relacionada a fatores físicos e ambientais que ao aspecto fisiológico (Hocking, 1989). No entanto, a influência negativa do nível mais alto de consumo de energia sobre a fertilidade pode ser justificada pelo excesso de energia armazenado em forma de gordura, que resulta no aumento do peso corporal e na redução da fertilidade. Apesar da importância do peso corporal no desempenho reprodutivo dos galos, é preciso reconhecer que a redução na fertilidade pode ser resultado de programas de alimentação visando somente atingir um ótimo padrão de peso vivo, sem a preocupação com a composição da carcaça do galo. 


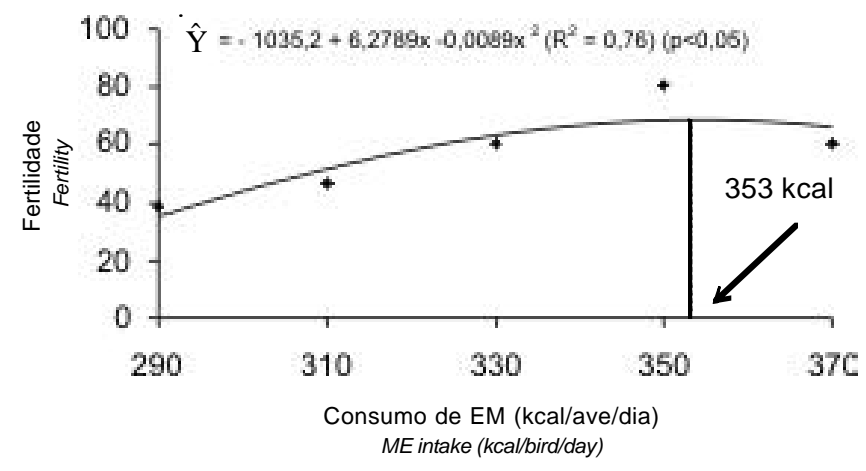

Figura 4 - Efeito do consumo de EM sobre a fertilidade de galos. Figure 4 - Effect of dietary ME intake on fertility of male broiler breeders.

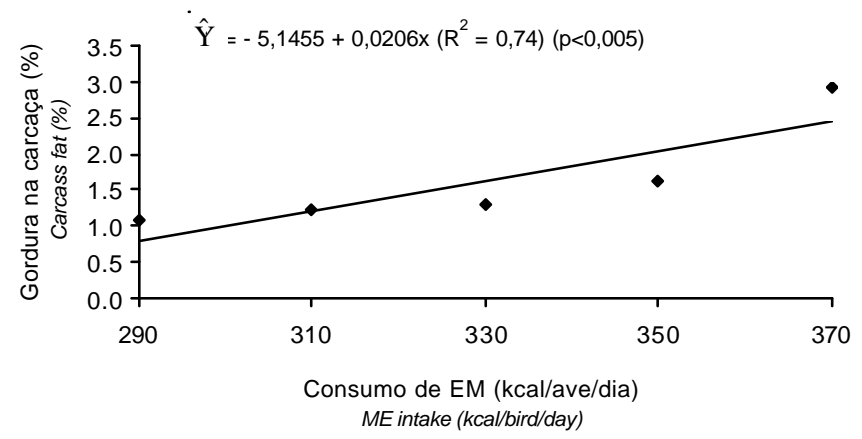

Figura 5 - Retenção de gordura na carcaça de galos, em função do consumo de energia.

Figure 5 - Effect of dietary ME intake on fat retention of male broiler breeders.

Avaliando os efeitos do consumo de energia dos galos reprodutores sobre as porcentagens de MS, gordura e proteína da carcaça aos 45 e 60 semanas de idade, verifica-se que não houve efeito significativo sobre a porcentagem de MS das carcaças dos galos nas duas idades.

Houve efeito linear (Figuras 5 e 6 ) do consumo de EM sobre a porcentagem de gordura $(\hat{Y}=-5,1455+0,0206 \mathrm{X}$, $\left.\mathrm{r}^{2}=0,74\right)(\mathrm{P}<0,05)$, indicando que os galos consumiram nível de energia superior à necessidade de mantença e o excesso foi transformado em reserva corporal na forma de gordura. Estes resultados corroboram os obtidos por Seaton et al. (1978) e Dale \& Fuller (1980). Também houve aumento da concentração de proteína corporal $(\hat{Y}=53,24+0,0502 X$, $\left.\mathrm{r}^{2}=0,82\right)$ à medida que o nível de ingestão de EM cresceu. Portanto, o aumento do consumo de EM elevou a retenção de gordura e de proteína na carcaça dos galos.

Este resultado fortalece a justificativa de que as aves consomem alimento para manter suas necessidades energéticas, de modo que o excesso de energia aumenta o peso corporal e a retenção de energia na carcaça, principal-

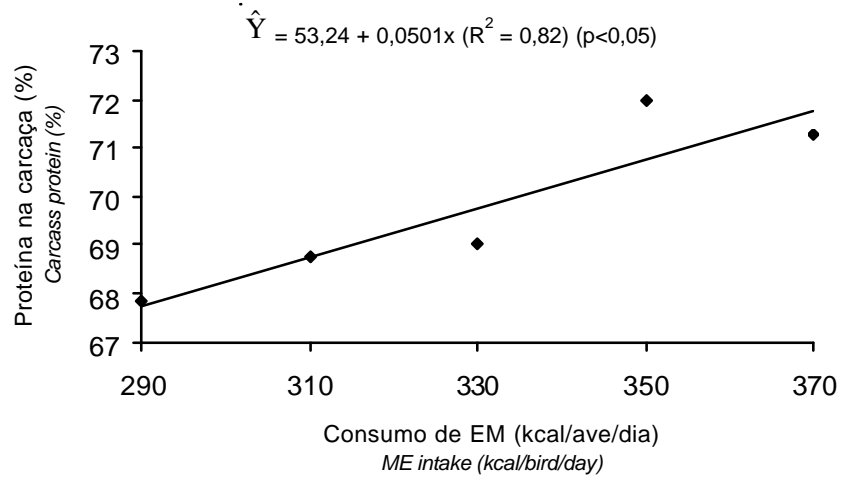

Figura 6 - Concentração de proteína na carcaça de galos em função do consumo de energia.

Figure 6 - Effect of dietary ME intake on crude protein concentration of male broiler breeders.

mente em aves adultas. Portanto, a gordura total da carcaça aumenta à medida que os machos consomem rações com níveis elevados de energia (Sexton et al., 1989).

O desequilíbrio crescente na relação energia:proteína da dieta com a elevação da EM foi a provável explicação para o aumento da adiposidade da carcaça dos galos, pois a EM cresceu enquanto a PB foi mantida fixa em todas as dietas. Portanto, nos níveis mais elevados de consumo, a energia excedente foi desviada com a finalidade de formar tecido adiposo. Vários autores têm demonstrado semelhante resultado (Leeson, 1999; Silva et al., 2001 e 2003).

A estimativa de $346 \mathrm{kcal} / \mathrm{kg}$ de EM/ave/dia obtida neste trabalho corresponde à concentração total de $2.660 \mathrm{kcal} / \mathrm{kg}$ da dieta, sendo pouco inferior aos $360 \mathrm{kcal} / \mathrm{dia}$ de EM recomendados por Rostagno et al. (2005) para galos consumindo diariariamente $130 \mathrm{~g}$ de ração.

\section{Conclusões}

Recomenda-se consumo de $346 \mathrm{kcal} / \mathrm{ave} / \mathrm{dia}$ de energia metabolizável para machos reprodutores de corte no período de 26 a 61 semanas de idade.

\section{Literatura Citada}

BELLAIRS, R.; OSMOND, M. The atlas of chick development. London: Academic Press, 1998. 323p.

BONGALHARDO, D.C.; DIONELLO, N.J.L.; LEDUR, M.C. et al. Parâmetros genéticos para caracteres de sêmen de aves White Leghorn. 2. Correlações com caracteres de postura. Revista Brasileira de Zootecnia, v.29, n.2, p.392-396, 2000.

BONI, I.J.; PAES, A.O.S. Programa de luz para matrizes: machos e fêmeas. In: SIMPÓSIO TÉCNICO SOBRE MATRIZES DE FRANGOS DE CORTE, 2., 1999, Chapecó. Anais... Chapecó: Embrapa, 1999. p.17-39.

BURROWS, W.H.; QUINN, J.P.The collection of spermatozoa from the domestic fowl and turkey. Poultry Science, v.16, p. 19-24, 1937. 
CEROLINI, S.; PIZZI, F.; GLIOZZI, T. et al. Lipid manipulation of chicker semen by dietary means and its relation to fertility: a review. World's Poultry Science Journal, v.59, n.1, p.65-75, 2003.

COUTO, H.P.; FONSECA, J.B.; ROSTAGNO, H.S. et al. Níveis de proteína em rações de galos reprodutores de corte. Revista Brasileira de Zootecnia, v.27, n.1, p.95-103, 1998.

DALE, N.M.; FULLER, H.L. Additivity of true metabolizable energy values as measured with roosters, broiler chicks, and poults. Poultry Science, v.59, p.1941-1942, 1980.

DANIKOWSKI, S.; SALLMANN, H.P.; HALLE, I. et al. Influence of high levels of vitamin $\mathrm{E}$ on semen parameters of cocks. Journal Animal Physiology and Animal Nutrition, v.86, p.376-382, 2002.

EDENS, F.W. Effect of environmental stressors on male reproduction. Poultry Science, v.62, p.1676-1689, 1983.

FROMAN, D.P.; BOWLING, E.R.; WILSON, J.L. Sperm mobility phenotype not determined by sperm quality index. Poultry Science, v.82, p.496-502, 2003.

FROMAN, D.P.; FELTMANN, A.J. Sperm mobility: a quantitative trait of the domestic fowl (Gallus domesticus). Biology of Reproduction, v.58, p.379-384, 1998.

HOCKING, P.M. Effect of dietary crude protein concentration on semen yield and quality in male broiler breeder fowls. British Poultry Science, v.30, p.935-945, 1989.

HOCKING, P.M.; DUFF, D.R. Musculo-skeletal lesions in adult male broiler breeder fowls and their relationships with body weigh and fertility at 60 weeks of age. Poultry Science, v.30, n.4, p.777-784, 1989.

LEESON, S. Energia para reprodutoras pesadas. In: CONFERÊNCIA APINCO’1999 DE CIÊNCIA E TECNOLOGIA AVÍCOLAS SIMPÓSIO INTERNACIONAL SOBRE NUTRIÇÃO DE AVES, 1999, Campinas. Anais... Campinas: Fundação APINCO de Ciência e Tecnologia Avícolas, 1999. p.25-39.

MARTIN RILLO, S.; MARTINEZ, E.; GARCIA ARTIGA, C. et al. Bora semen evalution in practive. Reproduction Domestic Animal, v.31, n.4, p.519-526, 1996.

McDANIEL, G.R. Manejo da alimentação e fertilidade em machos. In: CONFERÊNCIA APINCO`1997 DE CIÊNCIA E TECNOLOGIA AVÍCOLAS - SIMPÓSIO INTERNACIONAL SOBRE MANEJO DE MATRIZES E INCUBAÇÃO, 1997, Campinas. Anais... Campinas: Fundação APINCO de Ciência e Tecnologia Avícolas, 1997. p.69-71.

PEARSON, R.A.; HERRON, K.M. Effects of energy and protein allowances during lay on the reproductive performance of broiler breeder hens. British Poultry Science, v.22, p.227$239,1981$.

RENEMA, R.A.; ROBINSON, F.E.; FEDDES, J.J. et al. Effects of light intensity from photostimulation in four strains of commercial egg layers: 2 . Egg production parameters. Poultry Science, v.80, p.1121-1131, 2001

REVINGTON, W.H.; MORAN, E.T.; McDANIEL, G.R. Performance of broiler breeder males given low protein feed. Poultry Science, v.70, p.139-145, 1991.
RODENAS, C.E.O.; MURGAS, L.D.S.; MACIEL, M.P. et al. Características seminais de galos alimentados com rações suplementadas com diferentes óleos e níveis de vitamina $\mathrm{E}$. Ciência e Agrotecnologia, v.29, n.1, p.160-167, 2005.

ROSTAGNO, H.S.; ALBINO, L.F.T., DONZELE, J.L. et al.Tabelas brasileiras para suínos e aves: composição de alimentos e exigências nutricionais. Viçosa, MG: Universidade Federal de Viçosa, 2000. 141p.

ROSTAGNO, H.S.; ALBINO, L.F.T.; DONZELE, J.L. et al.Tabelas brasileiras para suínos e aves: Composição de alimentos e exigências nutricionais. 2.ed. Viçosa, MG: Universidade Federal de Viçosa, 2005. 186p.

RUTZ, F.; SAUL, I.; DIONELLO, N.J.L. et al. Desempenho reprodutivo de galos Leghorn submetidos a diferentes níveis de cálcio dietético. Revista Brasileira de Agrociência, v.5, n.2, p.120-123, 1999.

SAMARA, M.H., ROBBINS, K.R. SMITH, M.O. Interaction of feeding time and temperature and their relationship to performance of the broiler breeder hen. Poultry Science, v.75, p.34-41, 1996.

SEATON, K.W.; THOMAS, O.P.; GOUS, R.M. et al. The effect of diet on liver glycogen and body composition in the chick. Poultry Science, v.67, p.692-698, 1978.

SEXTON, K.J.; RENDEN, J.A.; MARPLE,D.N. et al. Effects of dietary energy on semen production, fertility, plasma testosterone, and carcass composition of broiler breeder males in cages. Poultry Science, v.68, p.1688-1694, 1989.

SILVA, D.J. Análises de alimentos (Métodos químicos e biológicos). Viçosa, MG: Universidade Federal de Viçosa, 1991. $166 \mathrm{p}$.

SILVA, J.H.V.; ALBINO, L.F.T.; NASCIMENTO, A.H. et al. Níveis de energia e relações energia: proteína para frangos de corte de 22 a 42 dias de idade. Revista Brasileira de Zootecnia, v.30, n.6, p.1791-1800, 2001.

SILVA, J.H.V.; ALBINO, L.F.T.; NASCIMENTO, A.H. et al. Estimativas da composição anatômica da carcaça de frangos de corte com base no nível de proteína da ração e peso da carcaça. Revista Brasileira de Zootecnia, v.32, n.2, p.344-352, 2003.

UNIVERSIDADE FEDERAL DE VIÇOSA - UFV.SAEG - Sistema para Análise Estatística e Genética. Versão 5.0. Viçosa, MG: Fundação Artur Bernardes, 1982. 59p.

WILSON, J.L.; McDANIEL, G.R.; SUTTON,C.D. Dietary protein levels for broiler breeder males. Poultry Science, v.66, p.237-242, 1987.
Recebido: 15/12/05 Aprovado: 06/06/06 